\title{
Rastros de cinema na teia literária urbana de Caio Fernando Abreu
}

\author{
[Cinema traces in Caio Fernando Abreu's urban literary web
}

\author{
Linda Kogure ${ }^{\mathrm{I}}$ \\ Milton Esteves Junior ${ }^{2}$
}

RESUMO - A meta é verificar de que forma os rastros de cinema são tecidos nos fios literários de "Pela noite", de Caio Fernando Abreu, e por que seus personagens olham o mundo como $s e$ fosse cinema. Seriam reflexos da própria conversão do mundo contemporâneo em rastros de cinema e/ou de simulacros, que incluem também outros elos da indústria cultural? Seriam reflexos de uma experiência urbana percebida como telas em movimento, fruto de vivências mediadas por vidros, janelas e para-brisas como se fossem lentes de câmeras? A novela é o ponto de partida para se repensar o quanto a indústria cultural tem alterado o comportamento humano, estabelecendo novas relações entre sujeito, mundo material e aparelhos destinados à reprodutibilidade técnica das imagens. • PALAVRAS-CHAVE • Cultura urbana/urbanização e literatura; simulacro e indústria cultural; Caio Fernando Abreu e rastros de cinema. ABSTRACT - The goal is to verify how the traces of the cinema are woven in the literary threads of the novel "Through the night", by Caio Fernando Abreu, and the reason why its characters face the world as if it were cinema. Would it reflect the very conversion of the world into cinema and/or simulacra traces, which also includes other links of the cultural industry? Would they be reflexes of an urban experience seen as moving screens, as a result of experiences mediated by windows and windshields, as if they were camera lenses? The novel is the starting point for rethinking how much the cultural industry has been changing human behavior, establishing new relations between subject, material world and apparatus for the technical reproducibility of images. - KEYWORDS - Urban culture/urbanization and literature; simulacrum and cultural industry; Caio Fernando Abreu and cinema traces.

Recebido em 27 de novembro de 2017

Aprovado em II de fevereiro de 2019

KOGURE, Linda; ESTEVES JUNIOR, Milton. Rastros de cinema na teia literária urbana de Caio Fernando Abreu. Revista do Instituto de Estudos Brasileiros, Brasil, n. 72, p. I84-I99, abr. 2019.

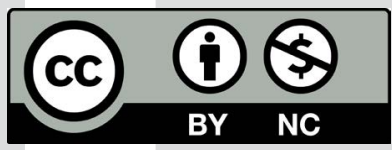

DOI: http://dx.doi.org/Io.II606/issn.23I6-90IX.voi72pI84-I99

I Universidade Federal do Espírito Santo (UFES, Vitória, ES, Brasil).

2 Universidade Federal do Espírito Santo (UFES, Vitória, ES, Brasil). 
Olhar, olhar, olhar é um cinema.

Caio F.

O objetivo é verificar de que forma Caio Fernando Abreu, o Caio F.3 tece rastros de cinema nos fios literários de "Pela noite" (ABREU, 2005b) e por que seus personagens olham o mundo como se fosse cinema. Aplica-se o conceito do como se por se tratar de literatura, arte regida: "A expressão 'como se' é central da teoria de Iser: 'pelo reconhecimento do fingir, [em que] todo o mundo organizado do texto literário se transforma em um como se' (em Costa Lima, I983: 400)" (BERNARDO, 2002, p. 77). Sendo assim, nessa novela, Caio F. intensifica sua peculiar fragmentação e os efeitos imagéticos - em movimento acelerado - e entrelaça os rastros cinematográficos em sua tessitura e no cotidiano urbano de seus outsiders e solitários. Dessa trama, emerge outro tipo de olhar contemporâneo, um olhar incapaz de observar o mundo sem mediações de uma lente, um projetor, um para-brisa ou uma tela: a vida, as ações em presente contínuo acelerado e multifacetado, as avenidas, as janelas, os automóveis, fragmentos da cidade, enfim, simulam projeções de telas urbanas em movimento. Outros elos da indústria cultural bombardeiam personagens e ambiências urbanas fragmentadas, aceleradas e saturadas de imagens multimidiáticas. Talvez essas personagens simbolizem também o vazio existencial e a solidão humana da grande metrópole.

"Pela noite”, ou seja, a literatura, nos guia como ponto de partida para repensar o quanto a indústria cultural, fortemente alicerçada na imagem, altera o comportamento humano ao estabelecer novas relações entre sujeito, mundo material e aparelhos destinados à reprodutibilidade técnica das imagens. E mais: ao apontar a crueza da solidão urbana nas grandes metrópoles, Caio F. traz à tona a busca desenfreada por uma afetividade perdida, dissimulada tanto na artificialidade

3 Assim assinou em mais de 80 epístolas, de 1980 a I996, quantitativo apenas da coletânea Caio Fernando Abreu: Cartas, organizada por Ítalo Moriconi (ABREU, 2002b). Ressalta-se, no entanto, que não se trata somente da rubrica em si. Vai muito além: foi a alternativa de Caio F. para abrir/criar personas/máscaras auto(alter)ficcionais tantas vezes em performance (work in progress), ou em jogos narrativos com alternância dos pronomes pessoais da primeira à terceira pessoa do singular. Foi também uma das estratégias para Caio F. transmutar-se em personagem de outros gêneros ficcionais, sobretudo, crônicas e cartas. 
dos rastros cinematográficos quanto no agito da multidão anônima da urbe. Rastros entendidos não como "uma presença, mas o simulacro de uma presença que se desloca, se transfere, se reenvia, ele não tem propriamente lugar, o apagamento pertence a sua estrutura" (DERRIDA, I99I, p. 58). Desse modo, desaparece em sua aparição. Nessa aparição, os rastros surgem no presente contínuo como "signo, signo do signo, rastro do rastro. [...] É rastro e rastro do apagamento do rastro"4 (DERRIDA, I99I, p. 58).

Antes de analisarmos de que forma esses rastros são tecidos em "Pela noite" (I983), publicada em Triângulo das águas ${ }^{5}$ (Prêmio Jabuti 1984), introduzimos breve sinopse: dois personagens mascaram seus nomes, tentam recriar suas identidades e passam a ser Pérsio e Santiago em alusão, respectivamente, à Crônica de uma morte anunciada, de Gabriel García Márquez, e a Os prêmios, de Julio Cortázar. Nascidos na (e foragidos da) cidade imaginária Passo da Guanxuma ${ }^{6}$, os dois se reencontram para curtir uma balada gay e viram "a noite de sábado pelo avesso da noite de julho" (ABREU, 2005b, p. I23). Talvez esse mascaramento represente o primeiro indício de simulação ou de dissimulação recorrentes na vida metropolitana: anonimato, privacidade, liberdade e cumplicidade. Talvez sugira um jeito mais descompromissado e seguro para aproveitar os desbundes, como diria Caio F., na agitação noturna paulistana, conforme acentua o narrador: "Do champanhe à cachaça, dos Jardins ao Jeca, do Off à Terra de Marlboro” (ABREU, 2005b, p. I23). Ou talvez seja um mascaramento para obliterar "essa armadilha de que não gostava, o passado abrindo súbito seu baú mofado para trazer de volta fantasmas esquecidos” (ABREU, 2005b, p. I40).

Só pela sinopse, indica-se que percorremos territórios híbridos, multimidiáticos, intertextuais e multirreferenciais, o que justifica certa clivagem adotada nesta abordagem centrada em dois grupos temáticos: I) o que compreende os conceitos de cidade e de cultura urbana que, embora não sejam o objeto central do corpus teórico deste artigo, são enunciados que não figuram como meros panos de fundo e sim no elenco de "Pela noite"; 2) e o que envolve o universo da imagem e da produção

4 Além do conceito de rastro aqui referido com base em Derrida, esses primeiros parágrafos já introduzem outros rastros conceituais, como indústria cultural, experimentação do mundo via simulações e mediações e reprodutibilidade técnica das imagens, temas há muito discutidos por autores como Debord, Adorno, Baudrillard, Virilio e Benjamin, entre outros tantos que, mesmo quando não citados, nos servem de referência.

5 Em função de Caio F. ter (re)revisado o livro em I99I para reeditá-lo, optamos pela última versão do autor (2005), que mantém a estrutura original, construída pelo viés da astrologia e como simbologia da água: a emoção.

6 O Passo da Guanxuma, cidade imaginária em formato de aranha assimétrica, foi criado em alusão a Santiago do Boqueirão (hoje, Santiago), berço do escritor, e é peça-chave na rede de fios que percorrem a sua vasta obra literária.

7 Esses referenciais urbanos deixam claro, no início da fiçãa, que a trama ocorre em São Paulo, numa trajetória que vai dos Jardins (América e Europa), lado nobre da cidade, até o submundo do centro, onde se localizavam o Bar do Jeca, no cruzamento das avenidas Ipiranga e São João, e o Clube Off, considerado o primeiro prive gay de São Paulo, e daí à “Terra de Marlboro” (provavelmente um epíteto para aquela "terra sem lei”). 
cinematográfica. Justamente porque ao longo de sua vasta obra literária ${ }^{8}$, Caio F. manteve outros diálogos cinematográficos ${ }^{9}$, além dos rastros de cinema que surgem e desaparecem velozmente no cotidiano de personagens imersos na vida urbana e na indústria cultural.

Neste artigo, não se pretende traçar paralelos entre técnicas de cinema ou cenas de filmes ${ }^{\text {IO }}$ que a ficção possa evocar ou entre o literário e o fenômeno urbano. $\mathrm{O}$ desafio é perseguir outras pistas não exploradas pela fortuna crítica de Caio F.: de que forma o escritor tece esses rastros que resultam nesse olhar contemporâneo como se fosse cinema? Seriam reflexos da própria conversão do mundo em simulacros e/ ou em rastros de simulacros? Seriam reflexos de uma experiência urbana percebida como telas em movimento, fruto de vivências mediadas por vidros, janelas e para-brisas como se fossem lentes de câmeras? Por essa via, pretende-se expandir não só o foco da fortuna crítica - com outras formas de análise -, como apontar também o quanto Caio F., ainda em I983 (sem internet ou celular), já absorvia esses fenômenos vivenciados na pele e na solidão urbana de suas criaturas, enredando-os em sua teia discursiva.

\section{TAKE I: O ENTRELAÇAR DOS FIOS NARRATIVOS NOS RASTROS DO CINEMA}

Mesmo antes de iniciar a narrativa, Caio F. introduz (sob o título) o primeiro rastro cinematográfico, ao sugerir Años de soledad como trilha sonora: "Years of solitude, de Astor Piazzolla e Gerry Mulligan)”. Embora o título dessa canção permaneça em elipse no começo da narrativa para ressurgir páginas depois, é essa trilha que embala o ritmo inicial já na primeira frase da novela: “- Como esta música - disse [Pérsio], aumentando o volume do som enquanto caminhava pela sala, abrindo os grandes vidros da janela para deixar o gemido do sax contaminar ainda mais o ar sujo das ruas, da noite, da cidade" (ABREU, 2005b, p. I09).

Años de soledad parece ter dupla estratégia: a) de Pérsio, como mote para simular sua performance $e^{\mathrm{II}}$, seguindo o andamento da trilha sonora para seduzir Santiago; e b)

8 Além de escritor de contos, novelas, romances, crônicas, cartas, poemas e letra de canção, Caio F. foi dramaturgo, tradutor, roteirista de televisão e jornalista.

9 Apenas alguns exemplos: Onde andará Dulce Veiga?: um romance B (I990), concebido como filme noir e adaptado em longa-metragem por Guilherme de Almeida Prado (2007); “Loucura, chiclete \& som", conto-simulacro de roteiro, publicado em Ovelhas negras (2002); "A verdadeira estória/história de Sally Can Dance (and the kids)", incluída em Pedras de Calcutá (1996).

Io Fabiano de Souza, por exemplo, pesquisou a relação entre a literatura do Caio e o cinema, em síntese, por três ângulos: I) a presença do cinema na obra, com paralelos entre os filmes citados e seus diretores, o que resultou num quadro de preferências cinematográficas do escritor e sua concepção sobre o cinema; aplicação de técnicas de montagem e de decupagem em narrativas de Caio que introduzem a linguagem cinematográfica; 2) a relação existencial do escritor com o cinema: o pesquisador relaciona o universo de Caio com reflexões de cineastas; 3) adaptações para o cinema e vídeos das narrativas do escritor (SOUZA, 20II).

II Entendido aqui pelo viés das artes cênicas: o corpo é o centro gravitacional da atuação do artista sempre ao vivo, com improvisação e interação com a plateia num ato de simulação (COHEN, 20II, p. IO6). 
de Caio F. para iniciar o entrelaçamento dos rastros de cinema na urdidura ficcional. Nota-se que Pérsio, primeiro, segue o ritmo do sax, contraindo o abdômen e todo o corpo, como se levasse um soco na boca do estômago. "O sax é o soco [...] [mas] Quando entra o bandoneon tudo se abre” (ABREU, 2005b, p. IIO) e todo o corpo se estende:

Foi então que num dos acordes bruscos [...] sem premeditar, num impulso esboçou um movimento de levantar-se do sofá. Antes de fazer o gesto já se via também erguendo-se, um filme em câmera lenta. Talvez três vezes, repetindo os mesmos fotogramas - gesto incompleto, gesto incompleto e gesto incompleto - até completá-lo: [...] o rosto devagar abaixado deixando desaparecer aos poucos uma imagem que se sobrepõe à outra, por um segundo ainda misturada à anterior, aquela expressão de gozo próximo [...]. (ABREU, 2005b, p. IIO).

Evidencia-se, assim, de que forma o escritor tece o "filme em câmera lenta" nos fios discursivos e no corpo do Pérsio. E o narrador prolonga a ação com o trio de repetições dos mesmos fotogramas do "gesto incompleto". No final, surge outra imagem em movimento lento, cuja duração se prolonga para permitir que o gozo, em vias de se consumar, permaneça por mais um segundo, sobrepondo-se a outra imagem para desaparecer. São rastros que se conectam à estética da interrupção, aquela que estrutura a consciência contemporânea alicerçada no fenômeno da cinemática: "Pois o cinema, arte do contínuo, paradoxalmente, retira toda a sua energia da interrupção" (VIRILIO; LOTRINGER, I984, p. 42). E, na literatura de Caio, essa energia é provocada pela excessiva e acelerada fragmentação, que corta e interrompe as ações em descrições/cenas imagéticas.

Virilio apropria-se da física para explicar que, além da energia potencial (presente na potência) e da energia cinética (que provoca o movimento), há outro fenômeno: a cinemática. Esta "resulta do efeito do movimento e de sua maior rapidez sobre as percepções oculares, ópticas e óptico-eletrônicas” (VIRILIO, I994, p. 89). No entanto, ele alerta que jamais existiu "visão fixa" e "a fisiologia do olhar depende do movimento dos olhos [...] incessantes e inconscientes (motilidade) e movimentos constantes e conscientes (mobilidade)" (VIRILIO, I994, p. 89). Outro tipo de olhar é o instintivo, que age por varredura completa e, por escapar ao controle rígido, seleciona seu objeto. É o que parece ocorrer aos olhos de Santiago como se fossem

[...] câmeras cinematográficas, com lentes capazes de aproximar ou afastar as imagens em zoom tornando às vezes mais definido o primeiro plano, agora a brasa [do cigarro] que tornava a subir para empastar em cores foscas, misturadas, indefinidas, as formas do fundo cortadas por alguma súbita cintilação [...] mastigava adjetivos como quindins, algum reflexo do semáforo no meio-fio da sarjeta transbordante de água suja dos bueiros (ABREU, 2005b, p. I55).

O narrador seleciona as imagens e as descreve como se fossem filme. Pouco importa que quindim seja um substantivo e não um adjetivo. Apenas se mastigam palavras/imagens que deslizam do interior do apartamento ao semáforo e/ou ao 
reflexo da rua. Ou mastigam-se rastros dos rastros já vistos, que retornam nessa visão. Visão que "começa no passado para iluminar o presente, [estabelecendo] o objeto de nossa percepção imediata” (VIRILIO, I994, p. 89). Assim, ao iluminar uma imagem/rastro do passado no presente, "Pela noite" desfaz a nitidez entre o real e o irreal. Pérsio, Santiago e o narrador vivenciam a ilusão de uma "nova naturalidade”, mergulhados na "superabundância de imagens como um novo elemento no qual respiramos como se fosse natural” (JAMESON, 2006, p. I35), classificado como o terceiro momento da teoria da visão ${ }^{\mathrm{I2}}$.

A nova situação que chamei de terceiro momento [...] apresenta agora problemas paradoxais. Ela significa uma mais completa estetização da realidade que é também, ao mesmo tempo, uma visualização ou colocação em imagem mais completa dessa mesma realidade. Entretanto, onde o estético impregna tudo, onde a cultura se expande até o ponto em que tudo se torna aculturado de uma ou outra forma, na mesma medida, o que se costumava chamar filosoficamente de distinção ou especificidade do estético ou da cultura tende, agora, a obscurecer-se ou a desaparecer completamente. (JAMESON, 2006, p. I35-I36).

Observa-se, assim, por que as personagens de "Pela noite" se submergem na realidade tão estetizada, já que não conseguem mais se distanciar da cultura imagética.

Retomemos a questão em suspenso sobre Años de soledad. Apesar da performance inicial de Pérsio, o título da canção só reaparece em outro lugar: numa pizzaria (a primeira parada) e simbolicamente em flashback, quando Santiago e seu parceiro recordam o reencontro da semana anterior, após décadas, numa sauna. Explica Pérsio: “quando vi, já tinha dito te espero às oito, não foi?” (ABREU, 2005b, p. I6o). E "você ligou hoje à tarde, aceitando" (ABREU, 2005b, p. I59). Mas Santiago chega meia hora antes. Diz Pérsio: "daí eu botei correndo aquela música, eu tinha que me mexer rápido":

- Como esta música.

- O quê?

- Como esta música, você disse. - Exatamente como esta música.

Pérsio parou de falar. Bebeu mais um gole de conhaque.

- Foi. Bem assim. Flashback na mosca, cara. Entra "Years of solitude" na trilha. Só uma vinheta, anos. Anos de solidão. Falar em flashback, sabe que às vezes tenho vontade de voltar para lá?. (ABREU, 2005b, p. I6I).

O primeiro momento é o colonial (ou sartriano): o tema do olhar associa- se à coisificação (reificação), quando o sujeito passa a ser um objeto. O segundo momento é o burocrático (foucaultiano): a "tentativa de Foucault de transformar uma política da dominação em uma epistemologia, e de ligar o saber e o poder tão intimamente como para torná-los inseparáveis, transforma assim o olhar em um instrumento de medição. $\mathrm{O}$ visível, portanto, passa a ser aqui o olhar burocrático que busca a mensurabilidade do outro e de seu mundo, doravante reificados" (JAMESON, 2006 p. I30). Essa etapa envolve os meios de comunicação que provocam uma metamorfose da própria imagem. 
Com o flashback associado a Años de soledad, Caio F. esclarece o porquê da improvisada performance de Pérsio e o afeto que Santiago preserva pelo Passo da Guanxuma, assumindo seu desejo de "voltar para lá". Por mais homofóbica ${ }^{\mathrm{T} 3}$ que a cidade seja, Santiago alimenta "anos de saudade" (ABREU, 2005b, p. I6I), enquanto Pérsio nem consegue se imaginar por lá. É também na pizzaria que Santiago desvela sua relação com o cinema, mas como refúgio da solidão:

Quase não vejo ninguém, quase não saio mais [...] [mas] vou ao cinema quase todo dia. Ou vejo uns dois filmes na televisão, cada noite. Já ando vendo as coisas, as coisas todas, o tempo inteiro como. Como se meus olhos fossem lentes. Dessas de cinema, um close, pá, vejo mais perto. Um zoom, pá, vou afastando. (ABREU, 2005b, p. I60).

A vida de Santiago está tão impregnada e estetizada pelo cinema que essa arte transforma-se em remédio para atenuar suas dores existenciais, a ponto de apropriar-se do artifício/simulação como se adicionasse lentes aos olhos. Assim, pode enquadrar/editar a visão e montar/transformar a realidade, alimentando a mera ilusão de viver a nova naturalidade, retomando Jameson.

Sigamos, agora, Pérsio e Santiago num travelling pelas ruas e avenidas de São Paulo.

\section{TAKE II: EM TRAVELLING NOTURNO}

A jornada sem destino de Pérsio e Santiago (este dirige o carro) não tem seu início preciso mas, ao seguir as pegadas da narrativa, começa na (rua e/ou avenida) Consolação e segue o citado percurso dos Jardins ao Centro. Pouco a pouco, fragmentos da cidade, pessoas, outdoors, tudo se transforma em "telas" em movimento:

Atrás, além do perfil dele [Pérsio], recortados contra a janela aberta, encobrindo por vezes as luzes que passavam, Santiago pôde ver primeiro a silhueta irregular dos edifícios, algum ponto de ônibus com pessoas encolhidas, amontoadas embaixo das marquises batidas pela garoa fina, um outdoor com dentes resplandecentes, outro com coxas morenas, volume salientes, cuecas, qualquer coisa, bares abertos, algumas putas [...] travestis [...], depois o início dos muros altos e brancos do cemitério [...] - desviando os olhos para baixo, para o asfalto, aquelas poças de água ${ }^{\mathrm{I} 4}$ colorida pelo neon, longo lago vertical ascendente, subindo através da rua, como se o carro fosse um barco navegando pela avenida, para cima, contra a correnteza [...]. (ABREU, 2005b, p. I54).

I3 Somente em "Pela noite”, Caio F. desvela o quanto a cidade imaginária é homofóbica no diálogo entre Pérsio e Santiago: “- Sabe que quando eu saía na rua as meninas gritavam biiiiiiiiicha! [...] - Era fresco que se dizia./ - Isso, Fresco, elas gritavam. Todas gritavam juntas. Ai, ai, elas gritavam. Bem alto” (ABREU, 2005b, p. I62). Pior: o barbeiro Benjamim não aguentou e se enforcou na figueira, no meio da praça e em pleno domingo de Páscoa. Foi encontrado pelo padre antes da missa.

I4 A simbologia da água é reforçada sob a forma de chuva que encharca personagens, alaga a cidade e forma poças espalhadas por ruas e avenidas, que refletem semáforos e anúncios luminosos. 
“Atrás, além do perfil" de Pérsio, que está no banco do carona com a janela aberta, induz o leitor a imaginar o ângulo de visão pela margem direita. Porém, o olhar de Santiago está multifacetado pelos retrovisores (interno e externo), o que embaralha a noção de localização: há reflexos e transparências dos espelhos, vidros, para-brisas etc. Vejamos outra sequência, por outro ponto de vista: "[...] Pérsio via agora, atrás e além dele a grande avenida cheia de carros em movimento, anúncios luminosos, a cidade encharcada, alagada" (ABREU, 2005b, p. I98). Mais um "atrás e além" para despistar a noção de localização pelas mesmas razões. Um terceiro exemplo é o do narrador ao descrever as "paisagens":

[...] deslizavam outra vez pelas mesmas ruas molhadas no caminho de volta, entre edifícios com algumas janelas iluminadas, recortes de cartolina, velhos filmes na televisão, Jane Wyman, Cornel Wilde, pessoas entrando, saindo de lugares barulhentos, semáforos colorindo as poças onde navegavam [...]. (ABREU, 2005b, p. 202).

Nas três sequências, Santiago, Pérsio e o narrador estão fora das cenas, isolados num carro vendo as imagens em travelling e, reiteramos, com o olhar mediado por vidros ou espelhos, como se fossem lentes de uma câmera ou telas de projeção. O narrador descreve as paisagens em telas, que, ao aparecer, desaparecem instantaneamente como os rastros de Derrida ou a estética da desaparição de Virilio. Não há mais passado, apenas o presente contínuo que desliza sem campo de profundidade. Não se percorrem espaços, apenas se passa por eles até chegar a algum lugar ou nenhum lugar.

Veículo e olhar se fundem nesse rápido deslizar que transforma tudo em imagens/espetáculos vivenciadas(os) num comportamento hipnótico. Caio F., que também sobreviveu como mass media, transborda em sua ficção o que Debord (I997, p. I8) conceitua como sociedade do espetáculo: "O espetáculo, como tendência a fazer ver [por diferentes mediações especializadas] o mundo que já não se pode tocar diretamente, serve-se da visão como o sentido privilegiado da pessoa humana [...]". O espetáculo, portanto, vai muito além de um mero conjunto de imagens, porque é um modo de interação entre as pessoas e o mundo real mediado por imagens. Um mundo à parte: é a própria cisão entre realidade e imagem, e entre verdade e ilusão, que promove a substituição da vida por simulações.

Em “Pela noite", essas simulações começam com o jogo de sedução na performance de Pérsio e com a farsa dos nomes próprios, conforme visto: Pérsio e Santiago são personagens de outras ficções. $O$ criador anula a identidade de suas criaturas num jogo de simulação e indica a substituição do real pelo espetacular. Por quê? O espetáculo que inverte o real é produzido na realidade, nesse caso, na ficção de Caio F.: "No mundo realmente invertido, a verdade é um momento do que é falso” (DEBORD, I997, p. I5-I6). Além de falsear os nomes de Pérsio e Santiago, rememoramos: Caio F. adiciona-lhes o olhar mediado por imagens abundantes e em movimento. E, quando esse excesso de 
imagens liberta-se dos referentes, passam a se processar como simulacros ${ }^{15}$, perdendo o caráter de cópia ou imitação, e migram do princípio da realidade para o regime da simulação.

A transformação de tudo em imagens aceleradas corresponde à conversão do mundo como se fosse cinema. "O que ocorre na janela do trem, no quebra-vento do carro, na tela da televisão é o mesmo tipo de cinematismo" (VIRILIO; LOTRINGER, I984, p. 82-83). Assim, os relatos de Pérsio, de Santiago e do narrador sem nome indicam sempre um conjunto de imagens em movimento, de simulacros e de rastros. Um conjunto de visões e de narrativas tecidas entre: são experiências entre o real e o irreal e/ou entre o vivenciado e o visto no cinema ou televisão. Ou do atual e do virtual, pelo viés do campo da multiplicidade, que "implica elementos atuais e elementos virtuais":

Não há objeto puramente atual. Todo atual se envolve numa névoa de imagens virtuais. Tal névoa se eleva de circuitos coexistentes mais ou menos extensos, sobre os quais as imagens virtuais se distribuem e correm. É assim que uma partícula atual emite e absorve virtuais mais ou menos próximos, de diferentes ordens. Eles são ditos virtuais à medida que sua emissão e absorção, sua criação e destruição acontecem num tempo menor do que o mínimo de tempo contínuo pensável, e à medida que essa brevidade os mantém, consequentemente, sob um princípio de incerteza ou de indeterminação. Todo atual rodeia-se de círculos sempre renovados de virtualidades, cada um deles emitindo um outro, e todos rodeando e reagindo sobre o atual. (DELEUZE; PARNET, I998, p. I74-I75).

Via literatura, Caio F. (2005b, p. III) revela as paisagens urbanas de São Paulo como circuitos entre o atual e o virtual: "antes de fazer o gesto [atual] já se via também erguendo-se, um filme em câmera lenta [virtual]". Nessa relação, "ora o atual remete a virtuais como a outras coisas em vastos circuitos, nos quais o virtual se atualiza; ora o atual remete ao virtual como a seu próprio virtual, nos menores circuitos nos quais o virtual cristaliza com o atual" (DELEUZE; PARNET, I998, p. I79).

Esse circuito remete ao referido olhar de Santiago, que, mesmo a olho nu, vê as coisas com lentes cinematográficas, numa tentativa de editar a visão para fugir da realidade atual e das amarguras vividas, ou para utilizar a percepção como intermediadora constante entre o atual e o virtual (suas lembranças ou imagens já vistas no cinema ou vividas) tantas vezes como névoas inconstantes:

I5 Baudrillard classifica os simulacros em três ordens: I) contrafação (do Renascimento à Revolução Industrial) em que vigorava a ordem natural do valor; 2) produção: "é o esquema dominante da era industrial”, onde o simulacro se mantinha na lei mercantil do valor; 3) simulação: faz parte da atual ordem "regida pelo código [e] opera sobre a lei estrutural do valor" (BAUDRILLARD, I996, p. 63). Quando a simulação transforma a imagem que um dia foi real em simulacro, o que vigora é o valor de troca, é a significação do valor simbólico dos objetos convertidos em imagens, em signos, simulações ou simulacros. 
Em virtude de uma identidade dramática dos dinamismos, uma percepção é como uma partícula: uma percepção atual se envolve de uma nebulosidade de imagens virtuais que se distribuem sobre circuitos moventes cada vez mais afastados, cada vez mais largos, que se fazem e se desfazem. São lembranças de diferentes ordens; elas são ditas imagens virtuais quando sua velocidade ou sua brevidade as mantém aqui sob um princípio de inconstância. (DELEUZE; PARNET, I998, p. I74-I75).

Essa névoa incessante de lembranças, de imagens virtuais e de sensações funciona como elementos deslizantes tanto na percepção de Santiago quanto do seu criador, que transpõe todas as fronteiras ao criar suas ficções.

Nota-se ainda que, em "Pela noite", a duração das imagens é curta, elas se justapõem contínua e instantaneamente em alternâncias de aceleração, velocidade e ritmo. Imagens que somem veloz e bruscamente, conforme o referido regime da estética da desaparição de Virilio, a exemplo de paradigmas que regem as atuais configurações urbanas, definidas por contornos difusos, descontínuos e dispersos, por paisagens ambíguas, imprecisas, fraturadas e desconexas. As atuais relações espaçotemporais, demarcadas por subsequentes demandas de aparelhos, dispositivos e infraestruturas que atendem à aceleração de fluxos, movimentos, deslocamentos e intercomunicações (de pessoas, mercadorias, capital e informações), estão levando a uma aceleração da velocidade que "está fazendo com que ela [a cidade] desapareça" (VIRILIO; LOTRINGER, I984, p. I7). É o paradoxo da velocidade: se de um lado ela une os fragmentos da cidade, de outro, ela faz com que a cidade desapareça como unidade, reaparecendo como sequência de fragmentos de um hiperespaço que só poderá ser captado virtualmente no âmbito das mediações e do imaginário. Assim, qualquer forma de experimentar ou expressar a cidade atual se apresentará à sua imagem e semelhança: fragmentada e mediatizada.

São efeitos também do citado cinematismo ${ }^{16}$, tratado aqui como fenômeno contemporâneo em função da reprodução da realidade projetada pela aceleração da velocidade tecnológica, que constrói o mundo como imagem/cinema, a exemplo de Caio F. É isso que deriva no efeito que Virilio define como dromoscopia ${ }^{\text {I7 }}$. Num mundo visto como cinema, ocorre a citada inversão da "estética pictórica da aparição [imagem estática] em estética de desaparecimento”, provocada quando a imagem estável se presentifica em sua fuga, graças à cinemática e a cinematografia. Resultado: "assistimos a uma transmutação das representações. À emergência de formas e volumes destinados a persistir na duração de seu suporte material, sucederam-se imagens cuja única duração é a persistência retiniana” (VIRILIO, 20I4, p. 2I).

I6 Embora o cinematismo seja o neologismo criado pelo cineasta Sergei Eisenstein para conceituar as interações entre o cinema e outras formas de manifestação artística, mesmo nas artes anteriores ao cinematógrafo, seguimos a perspectiva teórica de Virilio, sem entrar no mérito das técnicas de montagem do cinema, ecoando o já dito.

I7 Pela etimologia grega, dromos exprime a ideia de corrida, curso, marcha (VIRILIO, I996). Esse conceito se aplica também para nomear a atual dromomania, ou mania de vaguear numa vida errante, tal como as criaturas de Caio F. fazem. 
O cinematismo, portanto, inverte o que ocorre na pintura, que fixa a imagem na própria aparição. Já as imagens fílmicas surgem à medida que "desfilam a vinte e quatro imagens/segundo" (VIRILIO, 20I4, p. 83). E marcam presença porque somem velozmente no exato momento em que são percebidas, provocando "uma impressão de movimento. Existem porque são instáveis, porque escapam. Temos aí uma inversão da estética pictórica da aparição em estética do desaparecimento, uma estética foto-cinemato-vídeo-holográfica” (VIRILIO, 20I4, p. 83).

Ao traçar um paralelo entre a fotografia ${ }^{\mathrm{I} 8}$ e o cinema, Barthes (I984, p. I33-I34) explicita: embora haja "referente fotográfico", o cinema "desliza, não reivindica em favor de sua realidade, não declara sua antiga existência; não se agarra a mim”. Como o mundo real, o mundo fílmico é sustentado pela presunção de que "a experiência continuará constantemente a fluir no mesmo estilo constitutivo. [O cinema é] simplesmente normal como a vida" (BARTHES, I984, p. I34), tal como as cenas de "Pela noite".

Mas Virilio vai além ao afirmar que o cinema é como a nossa consciência: "é um efeito de montagem. Não existe consciência contínua, existem apenas composições de consciência” (I984, p. 42-43): as voluntárias, no sentido de atos conscientes que resultam de um desejo; e as inconscientes, como o sono e a "picnolepsia”.

Essas imagens urbanas funcionam em "Pela noite" como índices de uma cidade cujo nome é também outro rastro. Tanto é que Caio F. se refere à cidade por elipse: "Dois latino-americanos virando a noite pelo avesso da noite na noite da maior cidade da América do Sul” (ABREU, 2005b, p. I23). Também ao longo do travelling há citações que denotam signos que identificam a metrópole, além da citada Avenida da Consolação:

Quando o carro novamente avançou pela Faria Lima e ele pôde ver o relógio brilhando no escuro, no alto, duas horas e quarenta e três minutos, onze graus [...]. Atravessaram a avenida Paulista, alcançaram a descida ampla em direção às luzes da cidade, os muros altos do cemitério, as sombras emaranhadas das árvores [...] o grande anjo de braço erguido, mármore frio segurando a espada reluzente de chuva, a igreja recortada contra o céu [...]. (ABREU, 2005b, p. 204-205).

É curioso como Caio F. enriquece a atmosfera de suas cenas urbanas ao introduzir a luz cinematográfica nos fios narrativos:

Caminhou até a janela aberta e olhou o céu. Um luminoso da Coca-Cola brilhou ao longe, vermelho, branco: beba (ABREU, 2005b, p. II9).

No escuro, viu lá embaixo as cintilações dos faróis dos carros, anúncios luminosos, Minister, Melitta, Coca-Cola, fume, beba, compre, morra, suspensos no ar, flutuantes,

I8 A fotografia é “tirada em um fluxo, é empurrada, puxada incessantemente para outras vistas" (BARTHES, I984, p. I33.

I9 É o "ritmo da alternância da consciência e inconsciência, a interrupção picnolética (do grego picnos, 'frequente'), a qual ajuda-nos a existir numa duração que é nossa, da qual somos conscientes. Todas as interrupções estruturaram esta consciência e a idealizaram" (VIRILIO, 20I/, p. 4I). 
naves espaciais, janelas iluminadas nos outros edifícios, luzes às vezes vermelhoquente, íntimas como as das boates, vago erotismo nas silhuetas mal desenhadas [...], dezenas de metros abaixo as poças d'água no asfalto espelhavam o brilho artificial do neon. (ABREU, 2005b, I25).

A presença da luz tecida na narrativa destaca a propaganda, que bombardeia metrópole e personagens: cigarro, café, Coca-Cola e outras mercadorias surgem como ordens. E o narrador reitera: "fume, beba, compre, morra" (ABREU, 2005b, p. I25). Aliás, tanto a publicidade quanto todos os elos da indústria cultural marcam forte presença: a fonográfica, por exemplo, quando Santiago mexe nos discos de Pérsio e encontra

[...] Caetano, Gal, Duke Ellington, Armstrong, Stan Getz, Thelonious Monk, Marina, acariciou a capa de um Erik Satie, Silvia Telles, continuou mexendo, João Gilberto, Ray Charles, Dinah Washington, Elis, várias Elis, Dulce Veiga ${ }^{20}$, Nina Simone, Ângela Rô-Rô [...] um velho Mutantes, um Sérgio Sampaio” (ABREU, 2005b, p. I30 - grifos nossos).

Da indústria televisiva, "ligando a televisão no quarto, a música familiar, irritante, estridente do Jornal Nacional” (ABREU, 2005b, p. I29). Da mídia impressa, “laudas de jornal" dos tempos pré-informáticos e pilhas de revistas. Do setor editorial, livros, muitos livros. Dos rastros de cinema, citamos mais um: "tantas cores misturadas, saídos de um filme em preto e branco para a rua repleta de cores” (ABREU, 2005b, p. I56).

Já no veículo em movimento, Pérsio liga o rádio: "A voz de Roberto Carlos encheu o carro. Ele desligou” (ABREU, 2005b, p. I53). Volta a ligar o rádio. Gal Costa canta um "frevo nervoso. [...] procurou outra estação de rádio, a voz de Gal perdendo-se entre outras [...] até deter-se no piano lento [...]. A sonata número 4 de Beethoven” (ABREU, 2005b, p. I53-I54).

Assim, na contramão do que a mídia alardeia, há uma seleção/edição do que se consome: Beethoven a Roberto Carlos ou desligar a tevê na vinheta do Jornal Nacional. E não há restrição quanto à reprodutibilidade técnica nem a perda da aura da obra de arte ${ }^{2 \mathrm{I}}$ quando Pérsio ironiza a reprodução de O beijo, de Gustav Klimt, exposta em seu apartamento: "Trouxe de Paris, faz tempo. Tem muito por aí, só que esta é uma reprodução au-tên-ti-ca". E ele própria questiona: "Até que ponto uma reprodução pode ser autêntica?" (ABREU, 2005b, p. I27).

20 Salienta-se que Dulce Veiga, a cantora de "Nada além", a personagem mais recorrente de Caio F., só "nasceu" anos depois em Onde andará Dulce Veiga?, lançado em I990. É possível que o escritor estivesse em processo de "gestação" de sua criatura. Mesmo assim, a estrela da MPB marca presença entre reconhecidos músicos de diferentes gêneros musicais.

2I Aura como "figura singular" que garante a autenticidade, "a aparição única" do "aqui e agora" destruída pela reprodutibilidade técnica em série, cujo "agente mais poderoso é o cinema” (BENJAMIN, I986, p. I69-I70). 


\section{FINS: DESATANDO OS NÓS}

Ao tecer os rastros cinematográficos (e de outras mídias) entremeando-os em sua tessitura, Caio F. faz emergir os efeitos de como é olhar o mundo e viver o cotidiano como se fossem cinema, comprovando, via literatura, o pensamento dos teóricos citados até aqui. Sempre visceral, Caio aponta o quanto a sociedade contemporânea está contaminada pelo excesso de imagens, de informações e de bombardeios incessantes da indústria cultural (em acelerada velocidade); o quanto a artificialidade transforma-se em farsa natural e espetacular; o quanto o excesso de estetização - mediada pela reprodutibilidade técnica das imagens - altera as relações entre sujeito e mundo.

Ao perseguir os fios de "Pela noite", os enredamos aos de alguns teóricos para entender as influências, causas e efeitos que esse excesso de imagens espetaculares provoca na atual condição dos urbanitas, fadados às diversas ordens de experimentação fenomênica já citadas: substituição da vida por representações e do mundo material por signos; conversão dos signos em simulações, simulacros e seus rastros; substituição da reflexão pela ilusão de uma nova naturalidade; perda da percepção da realidade e da consciência produzida pela cinemática, além da aceleração da velocidade como cinematismo.

É preciso acrescentar que Caio F. manteve o hábito - no ato da criação - de imaginar a posição da câmera para descrever o ponto de vista exato em que as ações ocorrem. Não é por menos: o cinema foi um "protagonista na literatura e na vida do escritor. Cinéfilo, crítico, fã, vampiro de cinemateca [Caio] era um eterno inquilino da sala escura" (SOUZA, 20II, p. I2). Entretanto, conforme visto, não só o cinema se reflete e é tecido na teia de Caio: a música e toda a indústria cultural estão mescladas nos fios não só de "Pela noite" como em outros gêneros do escritor. Por esse viés, Caio F. é também um fiandeiro, que pratica a definição de Deleuze-Parnet (I998, p. 4I) sobre a função da escrita e do ato criativo: "escrever não tem outra função: ser um fluxo que se conjuga com outros fluxos - todos os devires-minoritários do mundo". Justamente porque a literatura de Caio está "entre", desenvolve "funções criadoras [...] que procedem por interseções, cruzamentos de linha, pontos de encontro no meio", mas sem especificidades por agregar "populações, música-escritura-audiovisual, com suas substituições, seus ecos, suas interferências de trabalho [...] como focos de criação" (DELEUZE-PARNET, I998, p. 38).

Absortos em tantos fluxos e linhas que se cruzam, reconhecemos: há fios soltos perdidos. Portanto, capturar é preciso. "Pela noite" não se restringe só aos efeitos provocados no olhar das personagens pela recorrência de imagens deslizantes, simulacros e seus rastros. Caio F. vai muito além: na novela, o olhar do narrador, de Pérsio e de Santiago inscreve também o corpo que se materializa, ou melhor, se constitui: ato que nos devolve "a crença no mundo" e nos faz "restituir a razão" (DELEUZE, 2005, p. 240). As duas faces coexistem de formas cambiantes e fragmentadas ao longo da ficção. Até porque Pérsio (crítico de teatro de jornal) e Santiago (professor) são personagens e, como tal, dotados de corpo, passado, memória, história de vida, 
medos $^{22}$, desejos, personalidades definidas etc. $\mathrm{O}$ oposto dos urbanoides em que eles esbarram na balada: "Tipo androides, em série. Vestem as mesmas roupas, usam o mesmo cabelo, dizem as mesmas coisas" (ABREU, 2005b, p. I90).

Citemos alguns exemplos: a performance de Pérsio é iniciada com o citado jogo de sedução, que mantém seu corpo como centro gravitacional. Logo depois, ao sair do banho, o sedutor ousa mais: exibe-se "completamente nu" (ABREU, 2005b, p. I43) aos olhos de Santiago, simulando a necessidade de escolher a roupa da noitada. Mais adiante, sutil, "[Pérsio] aproximou-se para tocá-lo, a ponta do dedo no ombro" (ABREU, 2005b, p. I48) de Santiago. Mas recua.

Na pizzaria, o sedutor que conduz a noite e fala sem parar, deixa "a ponta de um dedo roçar fugidia nos pelos macios das costas da mão de Santiago" (ABREU, 2005b, p. I58). Em frente à boate Deer's, "na esquina do ridículo, por dentro da noite" (ABREU, 2005b, p. 200), enfim, Santiago retribuiu o abraço de Pérsio: "um bicho arisco, abraçou-o com muita força, como se quisesse entrar dentro dele para poder compreendê-lo mais e melhor, inteiramente sozinhos no meio da chuva, assim mais poderosos" (ABREU, 2005b, p. 200). Ou entre insinuantes toques de mão: "morna, boa" (ABREU, 2005b, p. I2I), olhares que se cruzam (ABREU, 2005b, p. I2I), enfim, olhos, gestos, pele, corpo e carne estão em busca de um afeto, à procura da "pedra de toque, o Aleph, sephirot” (ABREU, 2005b, p. 225), como diz Pérsio ou, de forma mais mundana, em busca do amor carnal. Só que o amor parece estar "acima e além da esfera cotidiana: ele representa o universo do intangível, o sephirot, que, na tradição cabalística, constitui a árvore metafísica da vida ou dos dez atributos de Deus" (PEN, 2006, p. I4).

Todavia, o inatingível recua e possibilita que a procura do afeto/amor/carne se concretize. Fato que só ocorre quando os personagens dão um basta à encenação dos seus papéis: "Eu não me chamo Santiago" [...]. Eu também não me chamo Pérsio. Portanto, não nos conhecemos" (ABREU, 2005b, p. 226). Enfim, só se conheceram e se reconheceram como sujeitos quando "provaram um do outro no colo da manhã. E viram que isso era bom" (ABREU, 2005b, p. 226). Tão bom que deixam de ser meros espectadores do como se vissem ou editassem tantas imagens/rastros artificiais para saborearem a autenticidade natural da vida, dos afetos e dos prazeres dos seus corpos.

22 Pérsio tem "medo de ficar só, medo de não encontrar, medo da AIDS. Medo de que tudo esteja no fim, de que não exista mais tempo para nada. E da grande peste” (ABREU, 2005b, p. I88). Nos anos I980, a Aids estava associada a grupos de risco: gays, drogados e prostitutas. Segundo Marcelo Secron Bessa (I997, p. 5I), "Pela noite" é “possivelmente o primeiro texto literário brasileiro que trabalha com o tema da Aids”, tema fartamente explorado pela fortuna crítica do escritor gaúcho. 


\section{SOBRE OS AUTORES}

LINDA KOGURE é pós-doutoranda (bolsista da Capes) em Arquitetura e Urbanismo pelo Programa de Pós-Graduação em Arquitetura e Urbanismo da Universidade Federal do Espírito Santo (PPGAU/ UFES).

E-mail: linda.kogure@gmail.com

https://orcid.org/oooo-oooI-5890-5599

MILTON ESTEVES JUNIOR é doutor pela Universidade Politécnica da Catalunha (Barcelona) e professor do PPGAU/UFES.

E-mail: m.estevesg3@gmail.com

https://orcid.org/oooo-0003-392I-8384

\section{REFERÊNCIAS}

ABREU, Caio Fernando. Onde andará Dulce Veiga?: um romance B. São Paulo: Brasiliense, I990. . Pedras de Calcutá. São Paulo: Companhia das Letras, I996. . Ovelhas negras. Porto Alegre: LP\&M, 2002a. . Cartas. Organização de Italo Moriconi. Rio de Janeiro: Aeroplano, 2002b. . Triângulo das águas. Porto Alegre: L\&PM, 2005a. . (I983). Pela noite. In: . Triângulo das águas. Porto Alegre: L\&PM, 2005b, p. 105-226.

BARTHES, Roland. A câmara clara: nota sobre a fotografia. Rio de Janeiro: Nova Fronteira, I984. BAUDRILLARD, Jean. A troca simbólica e a morte. São Paulo: Edições Loyola, I996. BENJAMIN, Walter. Magia e técnica, arte e política. São Paulo: Brasiliense, I986. BERNARDO, Gustavo. Como se. Ipotesi: Revista de Estudos Literários da UFJF, Juiz de Fora, v. 6, n. 2, 2002, p. 75-89.

BESSA, Marcelo Secron. Histórias positivas: a literatura (des)construindo a Aids. Rio de Janeiro: Record, 20I7. COHEN, Renato. Performance como linguagem. São Paulo: Perspectiva, 20 II. DEBORD, Guy. A sociedade do espetáculo. Rio de Janeiro: Contraponto, I997. DELEUZE, Gilles. A imagem-tempo: Cinema 2. São Paulo: Brasiliense, 2005. ; PARNET, Claire. Diálogos. São Paulo: Escuta, I998.

DERRIDA, Jacques. Margens da filosofia. Campinas: Papiros, I99I.

JAMESON, Fredric. Espaço e imagem: teorias do pós-moderno e outros ensaios. Rio de Janeiro: UFRJ, 2006. PEN, Marcelo. Quem tem medo de Caio F?. In: Caio 3D: o essencial da década de I990. Rio de Janeiro:

Agir, 2006, p. 9-I6.

SOUZA, Fabiano de. Caio Fernando Abreu e o cinema. Porto Alegre: Sulina, 2011.

VIRILIO, Paul. A máquina de visão. Rio de Janeiro: José Olympio, I994. . Velocidade e política. São Paulo: Estação Liberdade, I996. . O espaço crítico. São Paulo: Editora 34, 20I4. 
. Estética da aparição. Rio de Janeiro: Contraponto, 2015.

; LOTRINGER, Sylvere. Guerra pura: a militarização do cotidiano. São Paulo: Brasiliense, I984. 